\title{
THE FATE OF UNFERTILIZED EGGS IN THE RABBIT
}

\author{
G. E. ADAMS \\ A.R.C. Unit of Reproductive Physiology and Biochemistry, \\ University of Cambridge
}

(Received 8th April 1970)

\begin{abstract}
Summary. The fate of the unfertilized egg was studied in a total of forty-five pseudopregnant rabbits, examined at autopsy at 24-hr intervals between Days 5 and 15. Throughout this period, egg recovery failed in only three animals and upwards of $50 \%$ of the eggs expected were recovered from the majority. The first signs of degeneration affecting the vitellus were noted about Day 5 and the process became marked during Days 7 to 10 .

In a further sixteen does in which either one or both oviducts were ligated shortly after ovulation, it was found that the trapped eggs were better preserved than their contemporaries which had entered the uterus at the normal time. Some eggs were still present in the ligated oviducts up to 30 days after ovulation. Recently ovulated one-cell eggs transferred to the uterus of recipients on the 9 th day of pseudopregnancy degenerated within $48 \mathrm{hr}$. It appears that the uterine environment is primarily responsible for the degeneration, particularly of the zona pellucida, rather than straightforward ageing of the egg.
\end{abstract}

\section{INTRODUCTION}

Observations are available on the initial degeneration of the unfertilized egg in several species (for references, see Blandau, 1961), but its ultimate fate has been investigated in only a few, including the rat (Blandau, 1943), pig (Dziuk, 1960), mouse (McLaren \& Orsini, 1968; McLaren, 1970) and sheep (Bindon, 1969). In the case of the rabbit, Pincus (1930) reported that he found it very difficult to recover unfertilized eggs from the uterus and concluded that "they are either rapidly resorbed or washed out into the vagina". However, during the course of a study involving pseudopregnant rabbits, it was observed that unfertilized eggs could be recovered from the uterus even up to 12 days after ovulation. It was therefore decided to put these observations on a more systematic basis. The fate of unfertilized eggs trapped by ligation in the oviduct was also investigated, as well as that of eggs transferred asynchronously to the uterus. In the rabbit, the eggs normally enter the uterus about 72 to $80 \mathrm{hr}$ post coitum (p.c.) (Gregory, 1930).

Postal address: 307 Huntingdon Road, Cambridge CB3 0JQ. 


\section{MATERIALS AND METHODS}

Observations were made on a total of sixty-four does. Ovulation was induced either by mating with a vasectomized male or by the intravenous injection of 25 i.u. human chorionic gonadotrophin-HCG (Lutormone, Burroughs Wellcome). The pseudopregnancy that follows normally lasts about 17 days.

In forty-five of the does (Group 1), eggs were recovered from the uterus at autopsy at $24-\mathrm{hr}$ intervals from Days 5 to 15 inclusive (Day $1=24 \mathrm{hr}$ p.c. or after $\mathrm{HCG}$ ).

In the remaining nineteen does (Group 2), either one or both oviducts were double ligated with cotton thread near the tubo-uterine junction within $12 \mathrm{hr}$ of ovulation. Subsequently, this group was treated as follows:

(a) In three recipient does, each with one ligated oviduct, one-cell eggs recovered from donors 1 or 2 days after mating with a vasectomized male were transferred to the uterine horn ipsilateral to the ligated oviduct on the 9th day of pseudopregnancy. Eggs were recovered from the uterus $48 \mathrm{hr}$ later.

(b) In seven unilaterally ligated does, eggs were recovered from the oviduct at autopsy on Day 9 (one doe), Day 11 (four does), or Day 12 (two does).

(c) Bilateral ligation of the oviducts was carried out in nine does.

On Day 20, 25 i.u. HCG were injected to induce a new set of ovulations, followed by double mating of six of the does with fertile males. Eggs were recovered from the oviducts 10 days later, i.e. on Day 30 relative to the first HCG treatment.

In these nineteen does, the ovulation points were counted at laparotomy and again as corpora lutea at autopsy, as in Group 1 does.

Eggs were recovered by flushing $10 \mathrm{ml}$ physiological saline through each uterine horn whilst in the case of the oviducts, $2 \mathrm{ml}$ were used. After location and preliminary examination, the eggs were mounted for photographic purposes.

\section{RESULTS}

Egg recovery from the uterus

Group 1 does. Details of the numbers of corpora lutea and of eggs recovered are given in Table 1 . With a few exceptions, more than $50 \%$ of the eggs expected to be present in the uterus were recovered during the period of observation, which spanned Days 5 to 15 . In some does, the total complement of eggs was recovered up to Day 14 . Only in three does $(7 \%)$ was no egg recovered at autopsy on Days 11,12 or 14 .

Morphologically, the eggs underwent marked degenerative changes with time. Plate 1 (Figs. A to I) and Plate 2 (Figs. K, M and O) show representative

\section{EXPLANATION OF PLATE 1}

The unfertilized rabbit egg

Fig. A: Recovered from the oviduct on Day $2(\times 195)$. Figs. B to I: Recovered from the uterus. B-Day 5, G-Day 6, D-Day 7, E-Day 8, F-Day 10, G-Day 11, H-Day 13, $\mathrm{I}-$ Day 14 . Figs. $\mathrm{E}$ and $\mathrm{I} \times 95$; others $\times 130$. 
PLATE 1
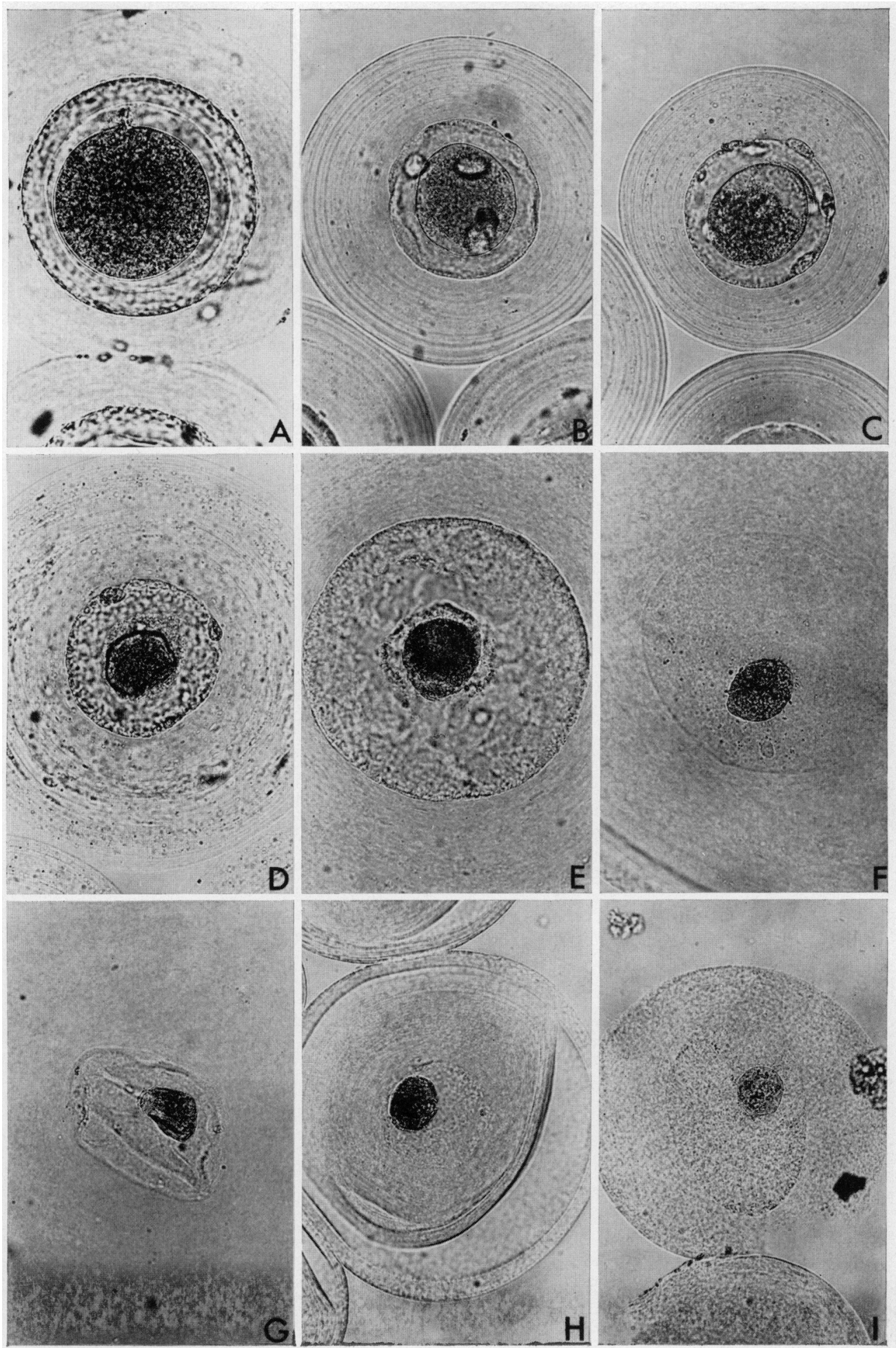

(Facing p. 320) 
PLATE 2
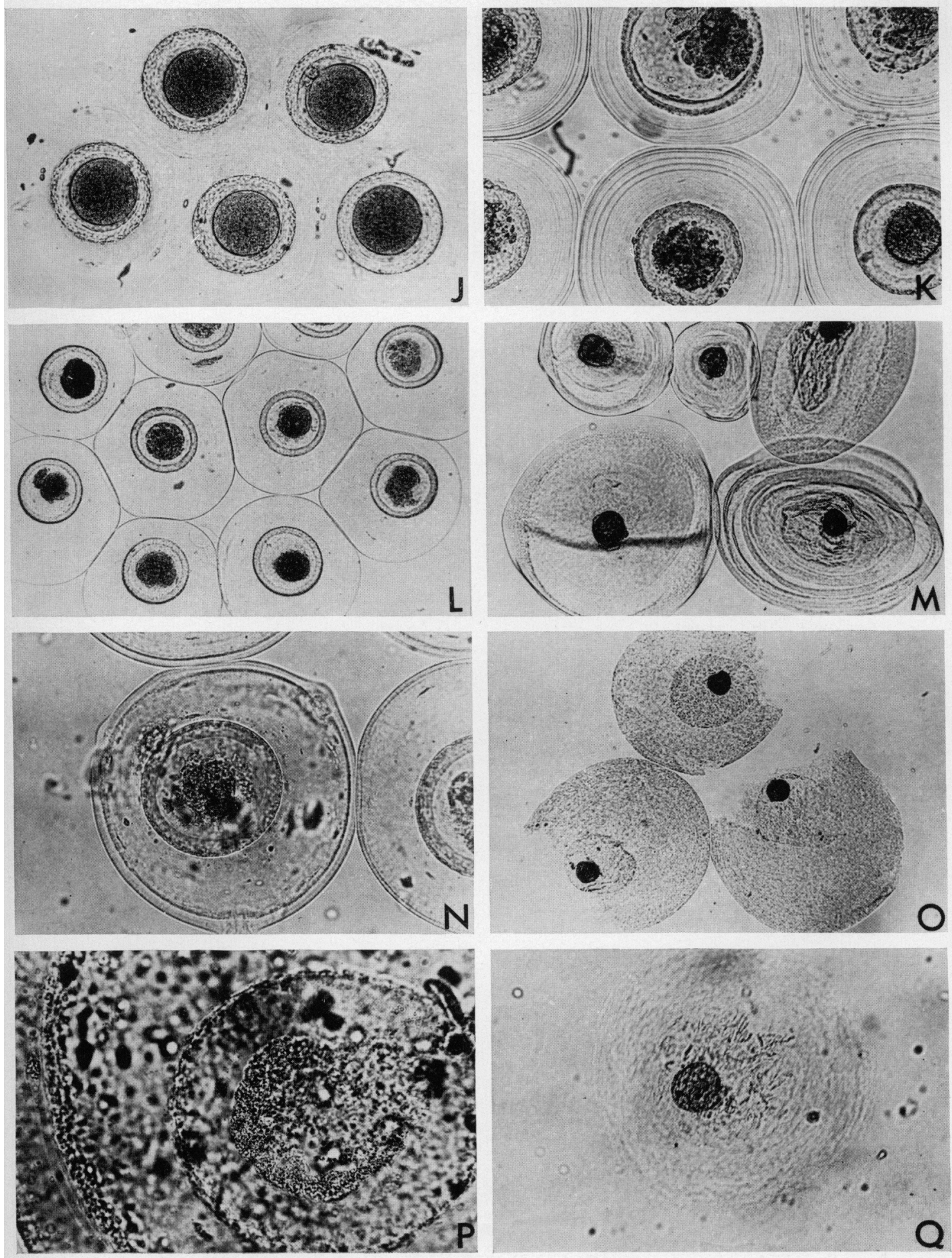

o 
examples of eggs recovered on Days 5 to 14 , with a young tubal egg included for comparison. The first part of the egg to be visibly affected was the vitellus, which showed signs of cytolysis already on Day 5 (Pl. 1, Fig. B). By Day 7 (P1. 1, Fig. D), the vitelline membrane was no longer identifiable and the inner aspect of the zona pellucida was becoming diffuse. The vitellus generally presented a shrunken appearance, occupying about one third to one half of the intra-zonal space. However, the overall dimensions of the egg (total diameter excluding the mucin layer) were still relatively unchanged. From Day 8 onwards, in an increasing proportion of eggs, the degenerative process was characterized by a further stage, which ultimately involved the disappearance of the zona pellucida and swelling of the area formerly bounded by the zona. There was a variation of about $48 \mathrm{hr}$ between animals in the time of onset of this process.

TABLE 1

RECOVERY OF UNFERTILIZED RABBIT EGGS DURING PSEUDOPREGNANCY

\begin{tabular}{c|c|c|c|l}
\hline Day & $\begin{array}{c}\text { No. of } \\
\text { does }\end{array}$ & $\begin{array}{c}\text { No. of } \\
\text { corpora lutea }\end{array}$ & $\begin{array}{c}\text { No. of eggs } \\
\text { recovered }\end{array}$ & \multicolumn{1}{|c}{$\begin{array}{c}\text { Egg recovery } \\
(\%)\end{array}$} \\
\hline 5 & 4 & 36 & 18 & $50 \cdot 0(9$ to 80$)$ \\
6 & 5 & 55 & 36 & $65.4(11$ to 100$)$ \\
7 & 4 & 43 & 28 & $65 \cdot 1(50$ to 77$)$ \\
8 & 4 & 53 & 32 & $60 \cdot 4(31$ to 100$)$ \\
9 & 6 & 71 & 42 & $59 \cdot 1(14$ to 90$)$ \\
10 & 4 & 41 & 24 & $58 \cdot 5(33$ to 80$)$ \\
11 & 5 & 58 & 21 & $36.2(0$ to 78$)$ \\
12 & 4 & 36 & 24 & $66.7(0$ to 100$)$ \\
13 & 3 & 32 & 22 & $68.7(40$ to 100$)$ \\
14 & 3 & 28 & 19 & $67.9(0$ to 100$)$ \\
15 & 3 & 29 & 6 & $20.7(7$ to 44$)$ \\
\hline
\end{tabular}

The vitellus was still present in eggs recovered up to Day 14 , but with the disappearance of the zona pellucida, it was free to move within the mucin. Application of slight pressure caused either disintegration of the vitellus or its liberation from the mucin, which lost its cohesive property and became fragile. Occasionally, eggs were observed in which the vitellus had disintegrated into a number of fragments of irregular shape and size. Regular fragmentation, such as might lead to confusion with normally cleaving eggs, was not encountered.

Group $2 a$. Following the transfer of sixteen recently ovulated one-cell eggs (P1. 2, Fig. J) to the '9-day' uterus, twelve were recovered after 2 days. Each of these eggs was in an advanced state of disintegration, as shown in Pl. 2, Fig. $Q$. Since all except one of the thirteen native eggs expected were recovered

\section{EXPLANATION OF PLATE 2}

The unfertilized rabbit egg

Fig. J-from the oviduct, Day $2(\times 90)$; Fig. $\mathrm{K}$-from the uterus, Day $6(\times 90)$; Fig. L-from the ligated oviduct, Day $12(\times 55)$; Fig. $M-$ from the uterus, Day 13 $(\times 90)$; Fig. N-from the ligated oviduct, Day 11 ( $\times 110)$; Fig. $\mathrm{O}-$ from the uterus, Day 14 ( $\times 55)$; Fig. P-from the ligated oviduct, Day 30 ( $\times 225)$; Fig. Q-'2-day' egg recovered $48 \mathrm{hr}$ after transfer to the uterus of a recipient on the 9th day of pseudopregnancy $(\times 150)$. 
from the ligated tubes, the identity of the transferred eggs was positively established.

\section{Egg recovery from the ligated tubes}

Group $2 b$. Of the eggs expected, three/three, seventeen/eighteen, and fifteen/ sixteen were recovered from the seven does examined on Days 9,11 and 12 respectively, giving an overall recovery rate of $95 \%$. All of these eggs were much better preserved than eggs of the same age recovered from the uterus (compare Pl. 2, Figs. L and M, N and O). Though the vitellus appeared very degenerate, the zona pellucida was quite clear and not distorted.

\section{TABLE 2}

THE RECOVERY OF EGGS FROM THE LIGATED TUBES OF DOES GIVEN LH 10 AND/OR 30 DAYS PREVIOUSLY

\begin{tabular}{c|c|c||c|c|c}
\hline Doe No. & $\begin{array}{c}\text { No. of } \\
\text { '30-day' } \\
\text { corpora lutea }\end{array}$ & $\begin{array}{c}\text { No. of } \\
\text { eggs } \\
\text { recovered }\end{array}$ & $\begin{array}{c}\text { No. of } \\
\text { '0-day' } \\
\text { corpora lutea }\end{array}$ & $\begin{array}{c}\text { No. of } \\
\text { eggs } \\
\text { recovered }\end{array}$ & $\begin{array}{c}\text { No. of } \\
\text { conceptuses } \\
\text { in utero }\end{array}$ \\
\hline 9965 & 12 & 5 & 12 & $10^{*}$ & 0 \\
9533 & 8 & 6 & 6 & $4^{*}$ & 0 \\
9401 & 11 & 0 & 13 & $6{ }^{\dagger}$ & 6 \\
9978 & 10 & 0 & 8 & 0 & 2 \\
9207 & 8 & 0 & 9 & 0 & 3 \\
9998 & 14 & 0 & 14 & 0 & 8 \\
\hline 9649 & 10 & 2 & & & \\
9853 & 10 & 3 & & & \\
\hline 8103 & 11 & 0 & & & \\
\hline
\end{tabular}

* One cell. † Degenerate early blastocysts.

Group 2c. Details of the nine does examined on Day 30 are given in Table 2. A total of eleven eggs ( $17 \%$ ), corresponding with the first set of ovulations which took place 30 days previously, was recovered from two out of six does. The vitellus was very degenerate, but the zona pellucida and mucin layer had persisted (Pl. 2, Fig. P). Eggs corresponding with the second set of corpora lutea, now 10 days old, were recovered in three does and, in one case, all six 'eggs' were degenerate early blastocysts, indicating that spermatozoa had entered the tube. Further, normal conceptuses were present in the contralateral horn, as was also the case in the other three does. Thus, in these animals, not only had spermatozoa entered the tubes but the fertilized eggs had gained access to the uterus at a time compatible with further development. As the ligatures were still in place at autopsy, it must be concluded that tubal patency was restored probably between the 12th and 23rd day after ligation.

Five eggs $(16 \%)$ were recovered from two of the remaining three does in which no attempt was made to induce a second set of ovulations. The eggs must, therefore, either have degenerated in the tubes or passed into the uterus, irrespective of the presence of new ovulations and/or fertilized eggs.

\section{DISGUSSION}

Three main findings have emerged from the present study. First, a good 
proportion of unfertilized eggs may persist in the uterus at least up to the 15th day of pseudopregnancy, contrary to the observations of Pincus (1930). Second, a characteristic sequence of degenerative changes occurs in the unfertilized egg. The marked deterioration that sets in about Days 7 to 10 is due to the developing hostility of the uterus rather than to ageing changes within the egg. Both young, unfertilized and fertilized tubal eggs are affected adversely by the advanced, progestational uterus (Adams, 1970). Third, if during the first 12 days of pseudopregnancy, the unfertilized egg is trapped within the oviduct, it is better preserved both numerically and structurally than in the uterus. This applies particularly to the zona pellucida. Up to the 12th day, almost all of the eggs expected were recovered from the ligated tubes, confirming an earlier finding (Adams, 1958). The recovery of fertilized sheep eggs 3 to 7 days after transfer to the ligated oviducts of oestrous rabbits is also reliable and efficient (Adams, Moor \& Rowson, 1968; Lawson, Rowson \& Adams, unpublished).

In the present study, few eggs were recovered from the tubes after 30 days, the longest interval examined. However, it cannot be concluded that the bulk of unfertilized eggs perish within 30 days, because the ligation was often only temporarily effective in restricting egg movement, apparently failing between Days 12 and 23. This aspect merits further consideration. The claim of Hensen (1869) to have recovered 100 rabbit eggs from a blocked oviduct is remarkable if considered in relation to the time, possibly 400 to 600 days, that it would have taken to accumulate so many eggs. Moreover, since ovulation is not spontaneous, it seems rather unlikely that any animal would have been mated the requisite number of times. A possible explanation is that mucin-covered bodies, which sometimes occur in large numbers in the oviduct, were wrongly identified as degenerate eggs. The horse is exceptional in that the unfertilized eggs in this species remain in the oviducts, where they have been found as long as $7 \frac{1}{2}$ months after ovulation (van Niekerk \& Gerneke, 1966). Failure to be transported normally into the uterus could be due to physical changes in the egg associated with degeneration. In the ewe for example, resin spheres, though similar in size to eggs, are not transported normally (Bennett \& Rowson, 1961).

\section{REFERENCES}

Adams, C. E. (1958) Egg development in the rabbit: the influence of post coital ligation of the uterine tube and of ovariectomy. F. Endocr. 16, 283.

Adams, C. E. (1970) Egg uterus interrelationships. In: Advances in the Biosciences, 4, pp. 149-162. Ed. G. Raspé, Pergamon Press, London.

Adams, C. E., Moor, R. M. \& Rowson, L. E. A. (1968) Survival of cow and sheep eggs in the rabbit oviduct. Proc. VIth Int. Congr. Anim. Reprod. and AI, Paris, 1, 573.

Bennetr, J. P. \& Rowson, L. E. A. (1961) The use of radioactive artificial eggs in studies on egg transfer and transport in the female reproductive tract. Proc. IVth Int. Congr. Anim. Reprod. and AI, The Hague, 2, 360 .

Bindon, B. M. (1969) Fate of the unfertilized sheep ovum. F. Reprod. Fert. 20, 183.

Blandav, R. J. (1943) The fate of the unfertilized ova in the albino rat. Anat. Rec. 87, 17.

BLANDAu, R. J. (1961) Biology of eggs and implantation. In: Sex and Internal Secretions, 3rd edn, p. 836. Ed. W. C. Young. Baillière, Tindall \& Cox, London.

Dziuk, P. (1960) Frequency of spontaneous fragmentation of ova in unbred gilts. Proc. Soc. exp. Biol. Med. 103, 91 .

Gregory, P. W. (1930) The early embryology of the rabbit. Contr. Embryol. 21, 141.

Hensen, J. (1869) Über die Züchtung unbefruchteter Eier. Zentbl. med. Wiss. 7, 403. Quoted by Blandau (1961), p. 837. 
Malaren, A. (1970) The fate of the zona pellucida in mice. F. Embryol. exp. Morph. 23, 1.

McLaren, A. \& Orsini, M. W. (1968) The fate of unfertilized eggs in mice. F. Reprod. Fert. 15, 181.

Pincus, G. (1930) Observations on the living eggs of the rabbit. Proc. R. Soc. B, 107, 132.

van Niekerk, G. H. \& Gerneke, W. M. (1966) Persistence and parthenogenetic cleavage of tubal ova in the mare. Onderstepoort. F. vet. Res. 31, 195. 